\title{
Analysis Of Errors In Limits Of Trigonometric Functions Among Students at King Saud University
}

\author{
Dr. Refat Abdelsamsd Abouelgheat Kandeel \\ Basic Science Department \\ King Saud University, Saudi Arabia
}

\begin{abstract}
The purpose of this study is to investigate the common errors in limits of trigonometric functions among the students at King Saud University, through analysis student responses at the items of the test, and to identify the varieties of the common errors and ratios of common errors that occurred in limits of trigonometric functions. The researcher prepared the open-ended test which consisted of (11) items about solving limits of trigonometric functions. The results showed there were a set of common errors in students' answers, the first common error was remembering mathematical rules, laws and theories associated with the limits of trigonometric functions, the next error was mathematical procedures conducted by the students while solving questions, then the conceptual and arithmetic errors, but by less than $20 \%$. Common errors have been determined accurately in each question of the test, as well as the number of students who made each error and the percentage of them.
\end{abstract}

Keywords: Limits, trigonometric functions, common errors.

\subsection{Introduce the Problem}

\section{INTRODUCTION AND THEORETICAL FRAMEWORK}

Mathematics has been associated with the cultural development of society by a positive relation with the growth and prosperity of mathematical science, if there was a civilized advanced society, it would be on the high degree of progress in mathematics. Mathematics is the science which has a reciprocal deal with modern information and technology revolution, where mathematics contributed to the outbreak of the revolution, it is also affected by the revolution where it responded to the revolution in the form of new mathematics branches, originated to meet the technology needs. Mathematics is necessary to understand the other branches of knowledge which based on mathematics by away or another way, and mathematics is the key to all science or art and specialty. Controlling and mastering of any science or art links to mathematics to benefit from it. Thus, we can say that mathematics is the mother of science and her servant.

Afana (1995) believes that "Mathematics is an active science and evolves and is renewed day after day like other sciences, modern mathematics did not come from a vacuum, but it was the result of a boom in intellectual and scientific development. Obaid (2004) believes that the development motivates in mathematics exist in two main ways: Eliminate the negative aspects and shortcomings and erroneous beliefs in the process of teaching and learning of mathematics and give it a great deal of vitality and applied it in life.

Calculus is a branch of mathematics taught Limits and differentiation, integration and infinite series, and it is the science used to study the change in the functions and analysis. It has two major branches, differential calculus (concerning rates of change and slopes of curves), and integral calculus (concerning accumulation of quantities and the areas under and between 
curves); these two branches are related to each other by the fundamental theorem of calculus. Both branches make use of the fundamental notions of convergence of infinite sequences and infinite series to a well-defined limit. Today, calculus has widespread uses in science, engineering and economics.

The limit of a function is a fundamental concept in calculus and analysis concerning the behavior of that function near a particular input. In mathematics, a limit is the value that a function or sequence "approaches" as the input or index approaches some value (Stewart, 2008). Limits are essential to calculus (and mathematical analysis in general) and are used to define continuity, derivatives, and integrals. The concept limit grew up in the context of the need to calculate the lengths and areas and volumes of forms such as circle and ball.The concept of limit in the simplest is the way to find a value that dependent variable must be taken it when the independent variable closed to a certain value.

For example: What is the value of $\frac{\sin x}{x}$ when $x$ closed to $(0)$ ?

It is clear that the direct compensation in this formula gives a quotient of $(0 / 0)$, which is the amount of non-specific, so note that the amount $\frac{\sin x}{x}$ less than (1) and greater than $\cos x$ for Any value of the variable $x$ is close to zero, and whereas $\cos (0)=1$, it is clear the limit of the amount $\frac{\sin x}{x}$ is (1).

Another example: If we assume that the independent variable $x$ is defined on the open interval (1.2) and close to the middle of this interval from the right $\left(1.5^{+}\right)$without reaching her, and accompanied by the function $f(x)=x-1.5$ approaches to (0) for example, it means that the limit of $f(x)$ is approaching to $(0)$ when the value of $x$ closed to $\left(1.5^{+}\right)$. If we assume that $f(x)$ is a real function and $c$ is a real number, then you can say $\lim _{x \rightarrow c} f(x)=L$. This means that the function $f(x)$ will be very close to $L$ when $x$ approaches to $c$, and express that the limit of $f(x)$ when $x$ approaches to $c$ is $L$.

Trigonometric functions is a branch of mathematics that deals with the relationships of sides and angles in triangles, forms an important background for the solution of problems in many disciplines (Orhun, 2010). Trigonometry is frequently used in mathematical explanations and definitions of new ideas and concepts. For example, trigonometric ratios are used to describe the relationship of angles and sides in a right-angled triangle.

Trigonometric functions is the most difficult functions that deal with the learner and able to find the limit of it, where it is difficult to remember the rules and laws for these functions, as well as their own algorithms consequent fall in the number of errors among a large number of learners when they try to find the limit of these functions.

There are many errors in mathematics, including common errors and others, and the many of researchers agreed that the common error which shows between $20 \%$ and $40 \%$ of learners, due to the prevalence of common errors in math, so many researchers has been made study and analyze these errors in order to process and reduce the appearance.

Research studies reveal that many students have not developed clear concepts in trigonometry and that some of them use algebraic notation informally (Maharaj, 2008). Siyepu (2015) study shows that errors displayed by students were conceptual and procedural; there were also 
errors of interpretation and linear extrapolation. Conceptual errors showed a failure to grasp the concepts in a problem and a failure to appreciate the relationships in a problem. Procedural errors occurred when students failed to carry out manipulations or algorithms, even if concepts were understood. Interpretation errors occurred when students wrongly interpreted a concept due to over-generalization of the existing schema. Linear extrapolation errors occurred when students over-generalized the property $f(a+b)=f(a)+f(b)$, which applies only when $f$ is a linear function, to the form $f(a * b)=f(a) * f(b)$, where $f$ is any function and $(*)$ any operation. The findings revealed that the participants were not familiar with basic operational signs such as addition, subtraction, multiplication and division of trigonometric functions. The participants demonstrated poor ability to simplify once they had completed differentiation.

Bicer, et al (2014) aimed to determine whether pre-service teachers have common difficulties and misconceptions about linear and quadratic inequalities. The study showed that a number of pre-service teachers struggled with the representing inequalities solution in number line. They added or excluded values in their solutions by drawing a blurred circle on a number line instead of an empty circle. Students also made basic arithmetic errors. The most common errors were addition, subtraction, multiplication, division and the distributive property. The results also indicate that not only the first year (pre-service teacher) possesses difficulties and misconception with linear and quadratic inequalities, but also second, third and fourth year pre-service teachers. The researchers due these misconceptions might be transitional from teachers to their students.

Muzangwa and Chifamba (2012) were going to analyze errors and misconceptions in an undergraduate course in Calculus. The study will be based on a group of $10 \mathrm{BEd}$, Mathematics students at the Great Zimbabwe University. Data is gathered through the use of two exercises on Calculus 1\&2.The analysis of the results from the tests showed that a majority of the errors were due to knowledge gaps in basic algebra. We also noted that errors and misconceptions in calculus were related to learners' lack of advanced mathematical thinking since concepts in calculus are intertwined. Also in this study, they highlight some common errors/ mistakes which can be done by lecturers during the teaching process. Students studying calculus often make the same mistakes and similarly lecturers teaching calculus have patterns of mistakes.

Ciltas and Tatar (2011) study aimed to diagnose the learning difficulties about the equation and inequality that contain absolute value. The results indicated that students have difficulties in forming a correct solution set and could not fully understand the concept of absolute value. Results also indicated that students experienced difficulties in applying the basic arithmetic operations, and interpreting the interval that is founded correctly in inequality questions.

Sawalha (2011) study aimed to identify the most common mathematical errors and its patterns for students with learning disabilities in mathematics in resource room. The sample consists of 140 male and female students: 69 from 4 th grade and 71 from 3rd grade. To achieve this goal the researcher prepared and applied a mathematical diagnostic test to the sample, and there were individual interviews. And to answer the questions of this study averages, standard deviations and two ways ANCOVA were used. The results showed there are common errors in fundamental concepts and algorithm and facts of addition, subtraction and multiplication. There is a statistically significant difference in common errors towards 3rd grade, and towards male sex, and there is no statistically significant difference in interaction between grade and type. 
Alshara' and Alabed (2010) study aimed at diagnosing errors that occurred in solving inequalities among mathematics majors at the University of Jordan. For the purpose of this study, one test was developed and administered to 188 male and female students majoring in mathematics who had completed Calculus 101.The results of this study revealed some common errors, such as: misconceptions, confusing an inequality with an equation, using commutative multiplication in solving inequalities, and changing the direction of inequality when multiplying by a negative number. Some other calculation errors and careless errors were also recorded. The common errors ranged between $5.7 \%$ for changing the direction of inequality when multiplying by a negative number, and $22.5 \%$ for conceptual errors. The study recommended that faculty members emphasize the subject of inequalities for freshmen and to administer tests in order to categorize them and develop the appropriate treatment plans.

Orhun (2010) states that students registered for calculus in their first year at a university perform badly in the operations of trigonometric expressions, namely addition, subtraction, multiplication and division. For example, students demonstrate difficulties in the multiplication of $\sin x \cdot \sin x$, and he argues that this may be due to the fact that there may not be much emphasis on the learning of addition, subtraction, multiplication and division of trigonometric functions in the secondary school curriculum.

Alqudah (2008) study aimed to classifying the common errors of the second secondary students' answers in mathematics 2006-2007 in Jourdan. Students' papers were corrected and errors were identified. The percentage of errors were calculated and it was $76.8 \%$, which indicates that students suffer from weakness in so many areas of the content of knowledge. The errors were classified into some categories by two stages; the first in each question of the exam and the second in all questions of the exam. The most common errors were classified into four main errors; conceptual errors, errors related to laws and theories, errors related to calculations and logical operations, and errors related to wrong hypothesis.

Elbrink (2007) said about her research: "After much research and discussion with mathematics educators, it is apparent that secondary education students make many common errors in mathematics. As a result, it is important to analyze what causes and how to address these mathematical errors so that teachers can correct and prevent these errors within the classroom. For my honors thesis, I briefly researched and analyzed the causes of mathematical errors in secondary education and ways to address students' errors. Then, through research, classroom observations, and discussions with secondary education teachers, I compiled a list of common student errors in mathematics and created activity sheets that address each error individually. I found that errors most often occur because not enough examples are considered. I am hoping that my knowledge of different mathematical representations will help me include numerous examples in future lessons to help prevent students from making mathematical errors in my classroom. Also, while working on my thesis, I came to realize how important it is to address errors within the classroom. Many of the errors that I addressed in my thesis were related to basic mathematical concepts that are the foundations on which students are expected to build their knowledge base as they progress through school. If these errors are not addressed, students will be trying to build their knowledge base of mathematics atop misunderstood concepts, which is not likely to prove successful.

Ureyen, et al (2006) Conducted a study to find out the errors committed by students in a course of Calculus in one of the Turkish universities when they are solving inequalities. The results of the study showed that students are unable to successfully resolve the inequalities, 
and that many of them time the disparate ends of a certain amount "cross-multiplication" without interested in a Sign of a variable, and the study recommended to provide feedback to students to know their mistakes and take advantage from them.

\subsection{The Problem of the Study}

In light of the literature review and studies relevant to Calculus, and errors which are located by the students, it is clear that some of these errors are common among students. This underlines the importance of analyzing errors and present the results to staff of Mathematics, these led the researcher to study and diagnose the common errors, and classify them among students of the preparatory year at King Saud University who study (Calculus) Course in the second semester 2015/2016.

\subsection{Study Questions}

- What are the common errors that occurred in limits of trigonometric functions among Students?

- What are the ratios of common errors in limits of trigonometric functions according to the type of a question?

\subsection{Importance of the study}

This study has a major role in the field of teaching limits of trigonometric functions and understanding them, as it determine the students' errors when you find the limits of trigonometric functions, which the student may benefit from them and tries to correct these errors, as well as the staff who guides taught to treat these errors with his students in the future.

\subsection{Objectives of the study}

This study aims to analyze the common errors in the limits of trigonometric functions occurred by the preparatory year students at King Saud University, through analyzing students' responses to the items on the study test, and identify the ratios of common errors.

\subsection{Limitations of the Study}

- The instrument which was developed by the researcher, so the interpretation of the results depends on the instrument's validity and reliability.

- Sample size: The study sample consisted of (211) students, distributes at (10) sections, it has been selected randomly.

- Male in the Preparatory Year at King Saud University in the second semester (2015/2016) that has completed studying the limits of trigonometric functions through Calculus Course (math 150).

\subsection{Procedural Definitions:}

King Saud University students: Male students who have been accepted in the preparatory year program at King Saud University and scientific track, totaling (3682) students who completed the study of Calculus Course (Math-150) in second semester 2015-2016.

Limit of a function: The value that a function or sequence "approaches" as the input or index approaches some value.

The trigonometric functions: A branch of mathematics that deals with the relationships of sides and angles in triangles. 
Common errors: Some studies suggest that a common error is an error that is repeated appearances in the students' answers. Khalifa (1983) said a common error is an error that the proportion of its prevalence (10\%), Alshara' and Alabed (2010) said more than (10\%), and Alqudah (2008) said more than (20\%) of the students who tried to answer the item. In the current study, the common error is an error that the proportion of its prevalence more than $(20 \%)$.

\section{METHOD AND PROCEDURES}

Descriptive approach has been used to get the data and facts about the nature of the student's common errors and ratios in the limit of trigonometric functions.

\subsection{The Study Sample}

The study sample consisted of (211) male students of scientific track in the Deanship of the preparatory year at King Saud University who study Calculus course (math-150) in the second semester (2015/2016), distributed in (10) sections, have been selected randomly.

\subsection{The Study Tools}

The study tool is a test about the limit of trigonometric functions, which was built in light of the expected errors and types of limits of trigonometric functions. The test included (11) essay items (open- ended questions) Appendix 1.

\subsection{Validity Tests}

To check the validity of the test was presented to a group of arbitrators, three PhDs in curriculum and methods of teaching mathematics, two PhDs in educational measurement and evaluation and (5) Lecturers of mathematics who have master degree in mathematics. After reviewing the opinions of the arbitrators and suggestions have been modified.

\subsection{Reliability}

The reliability computed by using test and re-test by applying the test on an exploratory sample consisted of (35) students who completed studying the limit of trigonometric functions throw (3) weeks. The Pearson correlation coefficient was (0.83) between the average performance of students in the first time and repetition.

\subsection{The Study Procedures}

- Review and analysis section of the limit of trigonometric functions in a Calculus course (Math $150)$ which studied by students in the preparatory year at King Saud University.

- Select (10) sections from (173) sections randomly, to represent the sample, with total (195) students.

- The first test application in the period ranged (from 50 to 60) minutes from the time of the lecture, where test consists of (11) items.

- Identify the key answer before starting the process of correction.

- Analyze the errors which appeared. The new errors that appeared have been added to the list, and continue correcting the same item to the end.

- Consider the error which has ratio more than (10\%) as the common error because all students in science track.

\subsection{Statistical Treatment}

Package statistical analysis of Social Sciences (SPSS) was used in the treatment of data. Frequencies and percentages were extracted to answer the questions of the study. 


\section{DISCUSS THE RESULTS AND ITS INTERPRETATION}

3.1 First question: What are the common errors in the limits of trigonometric functions among Students? To answer this question, the answer sheets of students were corrected to determine the types of the most common errors using frequencies and percentages, as shown in the following table:

Table (1): Frequencies, percentages and examples of error types

\begin{tabular}{l|c|c|c}
\hline Error type & $\mathrm{F}^{*}$ & $\mathrm{P}^{* *}$ & Example \\
\hline \hline The remembering error & 75 & 36.4 & Students didn't remember $1-\cos ^{2} x=\sin ^{2} x$ \\
\hline The procedural error & 70 & 34 & $\lim _{\substack{x \rightarrow 0 \\
\tan 3 x+\sin 2 x}} \lim _{x \rightarrow 0} \frac{4 x}{\tan 3 x}+\frac{4 x}{\sin 2 x}$ \\
\hline The conceptual error & 25 & 12.1 & Students didn't know the concept of continuity \\
\hline The arithmetic error & 21 & 10.2 & $\frac{\mathbf{O}}{\mathbf{O}}=\mathbf{O}$ or $\frac{\mathbf{1}}{\mathbf{O}}=\mathbf{1}$ \\
\hline
\end{tabular}

*Frequencies $\quad * *$ Percentages

Table 1 shows that the error of remembering rules, laws and theories is the most common error among students with a percentage prevalence (36.4\%), this followed by a procedural error with a percentage (34\%), The table also indicates there are conceptual and arithmetic errors among student in the limits of trigonometric functions, but their rates less than $20 \%$ because of the lack of concepts and complex calculations in this lesson.

Second question: What are the ratios of common errors in limits of trigonometric functions according to the type of a question? To answer this question, the answer sheets of students were corrected to determine the ratio of common errors in limits of trigonometric functions according to the type of a question using frequencies and percentages, as shown in the following tables:

Table (2): Frequencies, percentages and errors according to question 1.

\begin{tabular}{|c|c|c|c|c|}
\hline Question 1 & The type & $\mathrm{F}$ & $\mathrm{P}$ & The error \\
\hline Evaluate & Remembering & 48 & 23.3 & $\begin{array}{l}\otimes \lim _{x \rightarrow \pi / 2} x^{2}=(\pi / 2)^{2}=\pi^{2} / 2 \text { or } \pi / 4 \\
\text { instead of } \pi^{2} / 4\end{array}$ \\
\hline $\lim _{x \rightarrow \pi / 2} x^{2} \sin x$ & error & 67 & 32.5 & $\begin{array}{l}\otimes \\
\lim _{x \rightarrow \pi / 2} \sin (x)=\sin (\pi / 2)=0 \text { instead of } \\
=\sin (\pi / 2)=1\end{array}$ \\
\hline
\end{tabular}

Table (2) indicates that the average of students who have an error in remembering rules, laws and theories is (58) students, and the average of the percentage of this error is (33\%), but there isn't any procedural error among student in this question. Also, it is clear that the most common error among students is remembering $\sin (\pi / 2)=1$, where (67) students made this error, with a percentage (32.5\%).This followed by remembering the exponent laws, for example $(\pi / 2)^{2}=\pi^{2} / 2^{2}$, where (48) students made this error, with a percentage $(23.3 \%)$. 
Table (3): Frequencies, percentages and errors according to question 2.

\begin{tabular}{|c|c|c|c|c|}
\hline Question 2 & The type & $\mathrm{F}$ & $\mathrm{P}$ & The error \\
\hline \multirow{7}{*}{$\frac{1-\cos x}{x}$} & \multirow{4}{*}{$\begin{array}{l}\text { The } \\
\text { remembering } \\
\text { error }\end{array}$} & 72 & 35 & $\begin{array}{l}\otimes \text { Students didn't remember } \\
\qquad \lim _{x \rightarrow 0} \cos (x)=1\end{array}$ \\
\hline & & 86 & 41.7 & $\begin{array}{l}\otimes \text { Students didn't remember } \\
1-\cos ^{2} x=\sin ^{2} x\end{array}$ \\
\hline & & 64 & 31.1 & $\begin{array}{l}\otimes \text { Students didn't remember } \\
\qquad \lim _{x \rightarrow 0} \frac{\sin x}{x}=1\end{array}$ \\
\hline & & 74 & 35.9 & $\begin{array}{l}\otimes T_{\text {Students didn't remember using the }} \\
\text { conjugate } \\
\lim _{x \rightarrow 0} \frac{1-\cos x}{x} \cdot \frac{1+\cos x}{1+\cos x}\end{array}$ \\
\hline & \multirow{3}{*}{$\begin{array}{l}\text { The procedural } \\
\text { error }\end{array}$} & 48 & 23.3 & $\begin{aligned} \otimes & =\lim _{x \rightarrow 0} \frac{1-\cos x}{x} \cdot 1+\cos x \quad \text { instead of } \\
& =\lim _{x \rightarrow 0} \frac{1-\cos x}{x} \cdot \frac{1+\cos x}{1+\cos x}\end{aligned}$ \\
\hline & & 65 & 31.6 & $\begin{array}{l}\otimes \lim _{x \rightarrow 0} \frac{1-\cos x}{x} \cdot \frac{1+\cos x}{1+\cos x}=\lim _{x \rightarrow 0} \frac{1-\cos x^{2}}{x+\cos x^{2}} \\
\text { instead of }=\lim _{x \rightarrow 0} \frac{1-\cos ^{2} x}{x(1+\cos x)}\end{array}$ \\
\hline & & 84 & 40.8 & $\begin{array}{l}\otimes \lim _{x \rightarrow 0} \frac{\sin ^{2} x}{x(1+\cos x)}=\lim _{x \rightarrow 0} \frac{\sin ^{2} x}{x+x \cos x} \\
\text { instead of }=\lim _{x \rightarrow 0} \frac{\sin x}{x} \cdot \lim _{x \rightarrow 0} \frac{\sin x}{1+\cos x}\end{array}$ \\
\hline
\end{tabular}

Table (3) indicates that the average of students who have an error in remembering rules, laws and theories is (74) students, and the average of the percentage of this error is (36\%). The table also indicates that the average of students who have an error in the procedures is (66) students, and the average of the percentage of this error is (32\%). Also, it is clear that the most common error among students is remembering $1-\cos ^{2} x=\sin ^{2} x$, where (86) students made this error, with a percentage $(41.7 \%)$.This followed by a procedural error which appears while solving $\quad \lim _{x \rightarrow 0} \sin ^{2} x / x(1+\cos x) \quad$,where $\quad$ (84) students wrote $\lim _{x \rightarrow 0}\left(\sin ^{2} x / x(1+\cos x)\right)=\lim _{x \rightarrow 0}\left(\sin ^{2} x /(x+x \cos x)\right)$ instead of $=\left(\lim _{x \rightarrow 0} \sin x / x\right)\left(\lim _{x \rightarrow 0} \sin x / 1+\cos x\right)$. 
Kandeel, R. A. A. (2017). Analysis Of Errors In Limits Of Trigonometric Functions Among Students at King Saud University. Advances in Social Sciences Research Journal, 4(3) 47-62.

Table (4): Frequencies, percentages and errors according to question 3.

\begin{tabular}{|c|c|c|c|c|}
\hline Question 3 & The type & $\mathrm{F}$ & $\mathrm{P}$ & The error \\
\hline \multirow{3}{*}{$\begin{array}{l}\text { Evaluate } \\
\lim _{x \rightarrow 0} \frac{4 x}{\tan 3 x+\sin 2 x}\end{array}$} & \multirow{2}{*}{$\begin{array}{l}\text { The } \\
\text { remembering } \\
\text { error }\end{array}$} & 68 & 33 & $\begin{array}{l}\otimes \text { Students didn't remember } \\
\otimes \lim _{x \rightarrow 0} \tan 3 x=\tan (0)=0\end{array}$ \\
\hline & & 67 & 32.5 & $\begin{array}{l}\otimes \text { Students didn't remember } \\
\otimes \lim _{x \rightarrow 0} \sin (2 x)=\sin (0)=0\end{array}$ \\
\hline & $\begin{array}{l}\text { The } \\
\text { procedural } \\
\text { error }\end{array}$ & 97 & 47.1 & $\begin{array}{l}\otimes \lim _{x \rightarrow 0} \frac{4 x}{\tan 3 x+\sin 2 x}=\lim _{x \rightarrow 0} \frac{4 x}{\tan 3 x} \cdot \lim _{x \rightarrow 0} \frac{4 x}{\sin 2 x} \\
\text { instead of }=\lim _{x \rightarrow 0} \frac{\frac{4 x}{x}}{\frac{\tan 3 x}{x}+\frac{\sin 2 x}{x}}\end{array}$ \\
\hline
\end{tabular}

Table (4) indicates that the average of students who have an error in remembering rules, laws and theories is (68) students, and the average of the percentage of this error is (33\%). The table also indicates that the average of students who have an error in the procedures is (97) students, and the average of the percentage of this error is (47.1\%). Also, it is clear that the most common error among students is a procedural error which appears while solving $\lim _{x \rightarrow 0}(4 x /(\tan 3 x+\sin 2 x)) \quad$, where (97) students wrote $\lim _{x \rightarrow 0}(4 x /(\tan 3 x+\sin 2 x))=\lim _{x \rightarrow 0}(4 x / \tan 3 x) \cdot \lim _{x \rightarrow 0}(4 x / \sin 2 x)$ instead of $=\lim _{x \rightarrow 0}((4 x / x) /((\tan 3 x / x)+(\sin 2 x / x)))$.This followed by the common remembering error, where (68) students didn't remember $\tan (0)=0$. 
Table (5): Frequencies, percentages and errors according to question 4.

\begin{tabular}{|c|c|c|c|c|}
\hline Question 4 & The type & $\mathrm{F}$ & $\mathrm{P}$ & The error \\
\hline \multirow{9}{*}{$\begin{array}{l}\text { Evaluate } \\
\lim _{x \rightarrow 0} \frac{1-\cos x}{x \sin x}\end{array}$} & \multirow{5}{*}{$\begin{array}{l}\text { The } \\
\text { remembering } \\
\text { error }\end{array}$} & 72 & 35 & $\begin{array}{l}\otimes \text { Students didn't remember } \\
\otimes \lim _{x \rightarrow 0} \cos x=\cos (0)=1\end{array}$ \\
\hline & & 67 & 32.5 & $\begin{array}{l}\otimes \text { Students didn't remember } \\
\otimes \lim _{x \rightarrow 0} \sin x=\sin (0)=0\end{array}$ \\
\hline & & 74 & 35.9 & $\begin{array}{l}\otimes \text { Students didn't remember using conjugate } \\
\lim _{x \rightarrow 0} \frac{1-\cos x}{x} \cdot \frac{1+\cos x}{1+\cos x}\end{array}$ \\
\hline & & 86 & 41.7 & $\begin{array}{c}\otimes \text { Students didn't remember } \\
1-\cos ^{2} x=\sin ^{2} x\end{array}$ \\
\hline & & 64 & 31.1 & $\begin{array}{l}\otimes \text { Students didn't remember } \\
\qquad \lim _{x \rightarrow 0} \frac{\sin x}{x}=1\end{array}$ \\
\hline & & 56 & 27.2 & $\begin{array}{l}\otimes \lim _{x \rightarrow 0} \frac{1-\cos x}{x \sin x}=\lim _{x \rightarrow 0} \frac{1}{x}-\lim _{x \rightarrow 0} \frac{\cos x}{\sin x} \\
\text { instead of }=\lim _{x \rightarrow 0} \frac{1-\cos x}{x \sin x} \cdot \frac{1+\cos x}{1+\cos x}\end{array}$ \\
\hline & \multirow{3}{*}{$\begin{array}{l}\text { The } \\
\text { procedural } \\
\text { error }\end{array}$} & 65 & 31.6 & $\begin{array}{l}\otimes \lim _{x \rightarrow 0} \frac{1-\cos x}{x \sin x} \cdot \frac{1+\cos x}{1+\cos x}=\lim _{x \rightarrow 0} \frac{1-\cos x^{2}}{x+\sin x \cos x} \\
\quad \text { instead of }=\lim _{x \rightarrow 0} \frac{1-\cos ^{2} x}{x \sin x(1+\cos x)}\end{array}$ \\
\hline & & 78 & 37.8 & $\begin{array}{l}\otimes \text { Students can't simplify } \\
\lim _{x \rightarrow 0} \frac{\sin ^{2} x}{x \sin x(1+\cos x)} \text { to become } \lim _{x \rightarrow 0} \frac{\sin x}{x(1+\cos x)}\end{array}$ \\
\hline & & 76 & 36.9 & $\begin{array}{l}\otimes \lim _{x \rightarrow 0} \frac{\sin x}{x(1+\cos x)}=\lim _{x \rightarrow 0} \frac{1}{1+\cos x} \\
\text { instead of } \lim _{x \rightarrow 0} \frac{\sin x}{x} \cdot \lim _{x \rightarrow 0} \frac{1}{1+\cos x}\end{array}$ \\
\hline
\end{tabular}

Table (5) indicates that the average of students who have an error in remembering rules, laws and theories is (71) students, and the average of the percentage of this error is (34\%), and the table indicates that the average of students who have an error in the procedures is (69) students, and the average of the percentage of this error is (33\%). Also, it is clear that the most common error among students in this question is remembering $1-\cos ^{2} x=\sin ^{2} x$, and the next common error in this question is a procedural error which appears while simplify $\lim _{x \rightarrow 0}[\sin x /(x(1+\cos x))]$ to become $\lim _{x \rightarrow 0}\left[\sin ^{2} x /(x \sin x(1+\cos x))\right]$ where (78) students wrote this simplification by a wrong way. 
Table (6): Frequencies, percentages and errors according to question 5.

\begin{tabular}{|c|c|c|c|c|}
\hline Question 5 & The type & $\mathrm{F}$ & $\mathrm{P}$ & The error \\
\hline \multirow{5}{*}{$\begin{array}{l}\text { Evaluate } \\
\lim _{t \rightarrow \pi} \frac{\sin t}{\pi-t} \lim _{x \rightarrow \infty}\end{array}$} & \multirow{5}{*}{$\begin{array}{l}\text { The } \\
\text { remembering } \\
\text { error }\end{array}$} & 75 & 36.4 & $\begin{array}{l}\otimes \text { Students didn't remember } \\
\qquad \lim _{t \rightarrow \pi} \sin t=\sin \pi=0\end{array}$ \\
\hline & & 112 & 54.4 & $\begin{array}{l}\otimes \text { Students didn't remember } \\
\text { if } y=\pi-t \text { and } t \rightarrow \pi \Rightarrow \mathrm{y} \rightarrow 0 \\
\text { and } t=\pi-y\end{array}$ \\
\hline & & 125 & 60.7 & $\begin{array}{l}\otimes \text { Students didn't remember } \\
\lim _{y \rightarrow 0} \frac{\sin (\pi-y)}{y}=\lim _{x \rightarrow 0} \frac{\sin \pi \cos y-\sin y \cos \pi}{y}\end{array}$ \\
\hline & & 80 & 38.8 & $\begin{array}{l}\otimes \text { Students didn't remember } \\
\cos \pi=-1\end{array}$ \\
\hline & & 67 & 32.5 & $\begin{array}{l}\otimes \text { Students didn't remember } \\
\lim _{y \rightarrow 0} \frac{\sin y}{y}=1\end{array}$ \\
\hline
\end{tabular}

In this question, the average of students who have an error in remembering rules, laws and theories is (92) students, and the average of the percentage of this error is (45\%), but there isn't any a procedural error among student in this question. Also it is clear that the most common error among students is remembering $\sin (\pi-y)=\sin \pi \cos y-\sin y \cos \pi$, where (125) students made this error, with a percentage (60.7\%), followed by remembering: if $y=\pi-t$ and $t \rightarrow \pi \Rightarrow \mathrm{y} \rightarrow 0$ and $t=\pi-y$, where (112) students made this error, with a percentage (54.4\%).

Table (7): Frequencies, percentages and errors according to question 6.




This table indicates that the average of students who have an error in remembering rules, laws and theories is (84) students, and the average of the percentage of this error is (41\%), and the table indicates that the average of students who have an error in procedures is (63) students, and the average of the percentage of this error is (31\%), also it is clear that the most common error among students in this question is remembering $\cos 2 x=1-2 \sin ^{2} x$, where (64.1\%) of students didn't remember this rule. As (63) of students made a procedural error in this question, with a percentage (30.6\%), for example $\lim _{x \rightarrow 0}(x \tan x+\cos 2 x-1) / x^{2}=\lim _{x \rightarrow 0}(x \tan x / x)-\lim _{x \rightarrow 0}\left(2 \sin ^{2} x / x\right)$ instead of $=\lim _{x \rightarrow 0}\left(x \tan x / x^{2}\right)-\lim _{x \rightarrow 0}\left(2 \sin ^{2} x / x^{2}\right)$.

Table (8): Frequencies, percentages and errors according to question 7.

\begin{tabular}{|c|c|c|c|c|}
\hline Question 7 & The type & $\mathrm{F}$ & $\mathrm{P}$ & The error \\
\hline \multirow{6}{*}{$\begin{array}{l}\text { Evaluate } \\
\lim _{x \rightarrow 1} \frac{\sin (3 x-3)}{1-x^{3}}\end{array}$} & \multirow{5}{*}{$\begin{array}{l}\text { The } \\
\text { remembering } \\
\text { error }\end{array}$} & 86 & 41.7 & $\begin{array}{c}\otimes \text { Students didn't remember } \\
\sin (3 x-3)=\sin 3(x-1)\end{array}$ \\
\hline & & 75 & 36.4 & $\begin{array}{l}\otimes \text { Students didn't remember } \\
\qquad\left(1-x^{3}\right)=(1-x)\left(x^{2}+x+1\right)\end{array}$ \\
\hline & & 78 & 37.9 & $\begin{array}{l}\otimes \text { Students didn't remember } \\
(1-x)=-(x-1)\end{array}$ \\
\hline & & 99 & 48.1 & $\begin{array}{l}\otimes \text { Students didn't remember } \\
\text { if } x-1=y \text { and } \mathrm{x} \rightarrow 1 \Rightarrow \mathrm{y} \rightarrow 0\end{array}$ \\
\hline & & 75 & 36.4 & $\begin{array}{l}\otimes \text { Students didn't remember } \\
\lim _{y \rightarrow 0} \frac{\sin 3 y}{y}=3\end{array}$ \\
\hline & $\begin{array}{l}\text { The procedural } \\
\text { error }\end{array}$ & 95 & 46.1 & $\begin{array}{l}\otimes \lim _{x \rightarrow 1} \frac{\sin 3(x-1)}{(1-x)\left(x^{2}+x+1\right)}=\lim _{x \rightarrow 1} \frac{\sin 3}{\left(x^{2}+x+1\right)} \\
\text { instead of }=\lim _{x \rightarrow 1} \frac{\sin 3(x-1)}{(x-1)} \cdot \lim _{x \rightarrow 1} \frac{-1}{\left(x^{2}+x+1\right)}\end{array}$ \\
\hline
\end{tabular}

Table (8) indicates that the average of students who have an error in remembering rules, laws and theories is (83) students, and the average of percentage of this error is (46\%), and the table indicates that the average of students who have an error in procedures is (77) students, and the average of the percentage of this error is (37\%). Also, it is clear that the most common error among students in this question is remembering if $x-1=y$ and $\mathrm{x} \rightarrow 1 \Rightarrow \mathrm{y} \rightarrow 0$, and the next common error in this question is a procedural error which appears while solving $\lim _{x \rightarrow 1}\left[\sin 3(x-1) /\left((1-x)\left(x^{2}+x+1\right)\right)\right] \quad$, where the students wrote:

$\lim _{x \rightarrow 1}\left[\sin 3(x-1) /\left((1-x)\left(x^{2}+x+1\right)\right)\right]=\lim _{x \rightarrow 1}\left[\sin 3 /\left(x^{2}+x+1\right)\right]$, instead of

$\lim _{x \rightarrow 1}\left[\sin 3(x-1) /\left((1-x)\left(x^{2}+x+1\right)\right)\right]=\lim _{x \rightarrow 1}[(\sin 3(x-1)) /(x-1)] \cdot \lim _{x \rightarrow 1}\left[-1 /\left(x^{2}+x+1\right)\right]$. 
Table (9): Frequencies, percentages and errors according to question 8.

\begin{tabular}{|c|c|c|c|c|}
\hline Question 8 & The type & $\mathrm{F}$ & $\mathrm{P}$ & The error \\
\hline \multirow{4}{*}{$\begin{array}{l}\text { Evaluate } \\
\lim _{x \rightarrow 0} \frac{\tan 2 x}{\sqrt{3 x+1}-1}\end{array}$} & \multirow{2}{*}{$\begin{array}{l}\text { The } \\
\text { remembering } \\
\text { error }\end{array}$} & 68 & 33 & $\begin{array}{l}\otimes \text { Students didn't remember } \\
\lim _{x \rightarrow 0} \tan 2 x=\tan (0)=0\end{array}$ \\
\hline & & 65 & 31.6 & $\begin{array}{l}\otimes \text { Students didn't remember } \\
\lim _{x \rightarrow 0} \frac{\sin 2 x}{3 x}=\frac{2}{3}\end{array}$ \\
\hline & \multirow{2}{*}{$\begin{array}{l}\text { The procedural } \\
\text { error }\end{array}$} & 58 & 28.2 & $\begin{array}{l}\otimes \lim _{x \rightarrow 0} \frac{\tan 2 x}{\sqrt{3 x+1}-1} \cdot \frac{\sqrt{3 x+1}+1}{\sqrt{3 x+1}+1} \\
=\lim _{x \rightarrow 0} \frac{\tan 2 x(\sqrt{3 x+1}+1)}{9 x^{2}+1-1} \text { instead of } \\
=\lim _{x \rightarrow 0} \frac{\tan 2 x(\sqrt{3 x+1}+1)}{3 x+1-1}\end{array}$ \\
\hline & & 85 & 41.3 & $\begin{array}{l}\otimes \lim _{x \rightarrow 0} \frac{\tan 2 x(\sqrt{3 x+1}+1)}{3 x}=\lim _{x \rightarrow 0} \frac{\tan 2 x}{3 x} \cdot \lim _{x \rightarrow 0} \frac{(\sqrt{3 x+1}+1)}{3 x} \\
\text { instead of }=\lim _{x \rightarrow 0} \frac{\tan 2 x}{3 x} \cdot \lim _{x \rightarrow 0}(\sqrt{3 x+1}+1)\end{array}$ \\
\hline
\end{tabular}

The results of this question shows to the average of students who have an error in remembering rules, laws and theories is (67) students, and the average of the percentage of this error is (32\%). The table also indicates that the average of students who have an error in procedures is (85) students, and the average of the percentage of this error is (41\%). Also it is clear that the most common error among students is a procedural error which appears while solving $\quad \lim _{x \rightarrow 0}[(\tan 2 x(\sqrt{3 x+1}+1)) / 3 x] \quad$ where $(41.3 \%)$ of students wrote $\lim _{x \rightarrow 0}[(\tan 2 x(\sqrt{3 x+1}+1)) / 3 x]=\lim _{x \rightarrow 0}\left[(\tan 2 x / 3 x)\left(\lim _{x \rightarrow 0}((\sqrt{3 x+1}+1) / 3 x)\right)\right]$, instead of $\lim _{x \rightarrow 0}[(\tan 2 x(\sqrt{3 x+1}+1) / 3 x)]=\lim _{x \rightarrow 0}(\tan 2 x / 3 x) \cdot \lim _{x \rightarrow 0}(\sqrt{3 x+1}+1)$. The next error was a remembering error, where (68) students didn't remember $\tan (0)=0$. 
Table (10): Frequencies, percentages and errors according to question 9.

\begin{tabular}{|c|c|c|c|c|}
\hline Question 9 & The type & $\mathrm{F}$ & $\mathrm{P}$ & The error \\
\hline \multirow{4}{*}{$\begin{array}{l}\text { Find all values of } \\
k \text { such that }\end{array}$} & \multirow{3}{*}{$\begin{array}{l}\text { The } \\
\text { remembering } \\
\text { error }\end{array}$} & 75 & 36.4 & $\begin{array}{l}\otimes \text { Students didn't remember } \\
\qquad \lim _{x \rightarrow 0} \frac{\sin ^{2}(k x)}{x^{2}}=\lim _{x \rightarrow 0} \frac{\sin (k x)}{x} \cdot \lim _{x \rightarrow 0} \frac{\sin (k x)}{x}\end{array}$ \\
\hline & & 68 & 33 & $\begin{array}{l}\otimes \text { Students didn't remember } \\
\lim _{x \rightarrow 0} \frac{\sin (k x)}{x}=k\end{array}$ \\
\hline & & 51 & 24.8 & $\begin{array}{l}\otimes \text { Students didn't remember } \\
\text { if } k^{2}=4 \Rightarrow k= \pm 2\end{array}$ \\
\hline & $\begin{array}{l}\text { The } \\
\text { procedural } \\
\text { error }\end{array}$ & 55 & 26.7 & $\begin{array}{l}\otimes \lim _{x \rightarrow 0} \frac{\sin ^{2}(k x)}{x^{2}}=\lim _{x \rightarrow 0} \frac{\sin k}{x} \text { instead of } \\
\quad=\lim _{x \rightarrow 0} \frac{\sin (k x)}{x} \cdot \lim _{x \rightarrow 0} \frac{\sin (k x)}{x}\end{array}$ \\
\hline
\end{tabular}

This table indicates that the average of students who have an error in remembering rules, laws and theories is (65) students, and the average of the percentage of this error is (31\%), and the table indicates that the average of students who have an error in procedures is (55) students, and the average of the percentage of this error is (27\%), also it is clear that the most common error among students in this question is remembering $\lim _{x \rightarrow 0}\left(\sin ^{2}(k x) / x^{2}\right)=\lim _{x \rightarrow 0}(\sin (k x) / x) \cdot \lim _{x \rightarrow 0}(\sin (k x) / x)$, where (36.4\%) of students didn't remember this rule. As (55) students made a procedural error in this question, with a percentage (26.7\%), for example the students wrote $\lim _{x \rightarrow 0}\left(\sin ^{2}(k x) / x^{2}\right)=\lim _{x \rightarrow 0}(\sin k / x)$, instead of $\lim _{x \rightarrow 0}\left(\sin ^{2}(k x) / x^{2}\right)=\lim _{x \rightarrow 0}(\sin (k x) / x) \cdot \lim _{x \rightarrow 0}(\sin (k x) / x)$.

Table (11): Frequencies, percentages and errors according to question 10.

\begin{tabular}{|c|c|c|c|c|}
\hline Question 10 & The type & $\mathrm{F}$ & $\mathrm{P}$ & The error \\
\hline \multirow{4}{*}{$\begin{array}{l}\text { Find all values of } k \text { which } \\
\text { make }\end{array}$} & \multirow{3}{*}{$\begin{array}{l}\text { The } \\
\text { remembering } \\
\text { error }\end{array}$} & 72 & 35 & $\begin{array}{l}\otimes \text { Students didn't remember } \\
\text { if } f(x) \text { is continouos at } x=0 \Rightarrow \\
\lim _{x \rightarrow 0^{+}} f(x)=\lim _{x \rightarrow 0^{-}} f(x)=f(0)\end{array}$ \\
\hline & & 63 & 30.6 & $\begin{array}{l}\otimes \text { Students didn't remember } \\
\qquad \lim _{x \rightarrow 0} \frac{2 x}{\tan (k x)}=\frac{2}{k}\end{array}$ \\
\hline & & 53 & 25.7 & $\begin{array}{l}\otimes \text { Students didn't remember } \\
\qquad \begin{array}{l}k^{2}=2+k \Rightarrow k^{2}-k-2=0 \\
\Rightarrow(k-2)(k+1)=0\end{array}\end{array}$ \\
\hline & $\begin{array}{l}\text { The } \\
\text { procedural } \\
\text { error }\end{array}$ & 45 & 21.8 & $\begin{array}{c}\otimes k=\frac{2}{k}+1 \Longrightarrow k^{2}=2+1 \\
\text { instead of } \Longrightarrow k^{2}=2+k\end{array}$ \\
\hline
\end{tabular}

This table indicates that the average of students who have an error in remembering rules, laws and theories is (63) students, and the average of the percentage of this error is (30\%), and the table indicates that the average of students who have an error in procedures is (60) students, and the average of the percentage of this error is (29\%), also, it is clear that the most common error among students in this question is remembering 
if $f(x)$ is continouos at $x=0 \Rightarrow \lim _{x \rightarrow 0^{+}} f(x)=\lim _{x \rightarrow 0^{-}} f(x)=f(0)$, where $(35 \%)$ of students didn't remember this theory. As (45) of students made a procedural error in this question, with a percentage (21.8\%), for example, the students wrote $k=(2 / k)+1 \Longrightarrow k^{2}=2+1$ instead of $k=(2 / k)+1 \Rightarrow k^{2}=2+k$.

Table (12): Frequencies, percentages and errors according to question 11.

\begin{tabular}{|c|c|c|c|c|}
\hline Question 11 & The type & $\mathrm{F}$ & $\mathrm{P}$ & The error \\
\hline & & 76 & 36.9 & $\begin{array}{l}\otimes \text { Students didn't remember } \\
-1 \leq \sin \left(x+\frac{1}{x}\right) \leq 1\end{array}$ \\
\hline $\begin{array}{l}\text { Evaluate } \\
\lim _{x \rightarrow 0^{+}}\left(\sqrt{x} \sin \left(x+\frac{1}{x}\right)\right.\end{array}$ & $\begin{array}{l}\text { The } \\
\text { remembering } \\
\text { error }\end{array}$ & 65 & 31.6 & $\begin{array}{l}\otimes \text { Students didn't remember } \\
\text { if }-\sqrt{x} \leq \sqrt{x} \sin \left(x+\frac{1}{x}\right) \leq \sqrt{x} \text { and } \\
\lim _{x \rightarrow 0^{+}}-\sqrt{x}=\lim _{x \rightarrow 0^{+}} \sqrt{x} \Rightarrow \\
\lim _{x \rightarrow 0^{+}}-\sqrt{x}=\lim _{x \rightarrow 0^{+}} \sqrt{x}=\lim _{x \rightarrow 0^{+}} \sqrt{x} \sin \left(x+\frac{1}{x}\right)\end{array}$ \\
\hline
\end{tabular}

Table (12) indicates that the average of students who have an error in remembering rules, laws and theories is (71) students, and the average of the percentage of this error is (34\%), but there isn't any procedural error among student in this question. Also it is clear that the most common error among students is remembering $-1 \leq \sin (x+(1 / x)) \leq 1$, where (76) students made this error, with a percentage (36.9\%), followed by remembering the exponential laws, for example if $-\sqrt{x} \leq \sqrt{x} \sin (x+(1 / x)) \leq \sqrt{x}$ and $\lim _{x \rightarrow 0^{+}}-\sqrt{x}=\lim _{x \rightarrow 0^{+}} \sqrt{x} \Rightarrow \lim _{x \rightarrow 0^{+}}-\sqrt{x}=\lim _{x \rightarrow 0^{+}} \sqrt{x}=\lim _{x \rightarrow 0^{+}} \sqrt{x} \sin (x+(1 / x))$, where (65) students made this error, with a percentage (31.6\%).

\section{CONCLUSION AND RECOMMENDATIONS:}

This study aimed to identify common errors in limits of trigonometric functions among students at King Saud University and classification of these errors, so the researcher was prepared open test and apply it after the students finished lesson of limits of trigonometric functions, students' papers have been corrected to identify common errors.

This study showed to there were a set of common error in answers the questions of the test, the first common error was remembering rules, laws and mathematical theories associated with the limit of trigonometric functions, the next error was mathematical procedures conducted by the students while solving questions, then the conceptual and arithmetic errors, but by less than $20 \%$. Common errors have been determined accurately in each question of the test, as well as the number of students who made each error and the percentage of them. The researcher attributed these common errors to the weak of students' mathematical background, negative attitudes towards mathematics, and staff didn't focus on teaching mathematical rules, laws and theories during the explanation.This study recommends to prepare remedial program for students to treat all the common error that appeared in this study, and training Staff on methods of prevention their students in these errors in the future, and further studies to identify the common errors of students in other math lessons. 


\section{References}

Afaneh, I. I. (1995). Strategic teaching of modern mathematics, College of Education, $1^{\text {st }}$ Ed, the Islamic University of Gaza.

Obaid, W. (2004). Mathematics education for all children, $1^{s t}$ Ed, Dar Elmasera for Publishing and Distribution, Amman.

Stewart, J. (2008). Calculus: Early Transcendentals (6th Ed.). Brooks/Cole. ISBN 0-495-01166-5.

Orhun, N. (2010). The gap between real numbers and trigonometric relations. Quaderni DI Ricerca in Didattica, 20, $175-184$.

Maharaj, A. (2008). Some insights from research for teaching and learning mathematics. South African Journal of Education, 28, $401-414$.

Siyepu, (2015). Analysis of errors in derivatives of trigonometric Functions, International Journal of STEM Education, DOI 10.1186/s40594-015-0029-5

Bicer, A.; Capraro, R. and Capraro, M. (2014). Pre-service teachers' linear and quadratic inequalities understandings. International Journal for Mathematics Teaching and Learning. http://www.cimt.plymouth.ac.uk/journal/default.htm

Ciltas, A. and Tatar, E. (2011). Diagnosing learning difficulties related to the equation and inequality that Contain terms with absolute value. International Online Journal of Educational Sciences, 3 (2)461-473.

Al-Shara', I. and Al-Abed, A. (2010). Analysis of errors in solving inequalities among mathematics' students at the University of Jordan. Jordan Journal of Educational Science, 6(2), p 93-108.

Elbrinkm M.(208). Analyzing and addressing common mathematical errors in secondary education, Extended Thesis Abstracts, B.S. Undergraduate Mathematics Exchange, V. 5, No. 1

http://www.bsu.edu/libraries/beneficencepress/mathexchange/0501/Elbrink.pdf

Ureyen, M., Mahir, N. and Cetin, N. (2006). The mistakes made by the students taking a calculus course in solving inequalities. Electronic International Journal for Mathematics Teaching and Learning, November30th.

From://http://www.cimt.plymouth.ac.uk/journal/ureyen.pdf

Muzangwa, J. and Chifamba, P. (2012). Analysis of errors and misconceptions in the learning of calculus by undergraduate students, Acta Didactica Napocensia, ISSN 2065-1430.

http://dppd.ubbcluj.ro/adn/article_5_2_1.pdf

Khalifa, K. (1983). Research in teaching mathematics. First volume, Dar Alkitab Al Jamie, Cairo, Egypt.

Alqudah, A. H. (2008). Classifying the common errors in the secondary students' in mathematics' answers 2006-2007 in Jourdan, Journal of Education College, Al-Azhar University, No. 136 Part I. pp 627-645.

Sawalha, A. (2011). Identify the most common mathematical errors and its patterns among students with learning disabilities in mathematics in resource room, Journal of Educational Sciences, Vol. 38, App.7, pp 2344-2365. 